\title{
Interdisciplinaridade e integração dos saberes ${ }^{1}$
}

\section{Olga Pombo*}

Resumo Com o objectivo de contribuir para a superação da equivocidade que envolve o conceito de interdisciplinaridade, começamos por uma proposta de estabilização do sentido da palavra. Num segundo momento, procura-se mostrar que aquilo que explica o carácter recorrente com que o conceito, apesar de equívoco, continua a ser utilizado, é a procura de uma resposta positiva para o fenómeno avassalador da especialização, a tentativa de ultrapassar os graves cultos culturais, institucionais e heurísticos dele decorrentes. Finalmente, defende-se que a interdisciplinaridade é a manifestação de uma transformação epistemológica em curso e apontam-se aquelas que nos parecem ser as suas duas consequencias principais: o alargamento do conceito de ciência e a transformação da Universidade.

Palavras-chave Interdisciplinaridade, especialização, heurística, epistemologia, universidade.

\begin{abstract}
Aiming to contribute to the overcoming of the equivocity in which is involved the concept of interdisciplinarity; we begin by a proposal of stabilization of its meaning. In a second moment, we try to explain the recursive use of this concept by the search of a positive answer for specialization, that is, by the attempt of overcoming its serious cultural, institutional and heuristic costs. At last, we stress the thesis according to which interdisciplinarity corresponds to a deep epistemological transformation which is taking place nowadays and we indicate those we consider to be the its two main consequencies: the enlargment of the concept of science and the transformation of University.
\end{abstract}

Keywords Interdisciplinarity, specialization, heuristics, epistemology, university.

Permitam-me que comece com uma observação preliminar: estou aqui sobretudo para aprender convosco. Não se trata de uma fórmula retórica adequada para abrir uma conferência ou sequer de um discreto cumprimento à Universidade que me convidou ou ao auditório que me escuta. Não! O que se passa é que, ao contrário de Portugal onde as investigações e experiências interdisciplinares são recentes e muito restritas, no Brasil há uma tradição ampla e já longa de trabalho interdisciplinar, tanto na investigação como no ensino. ${ }^{2}$ Neste momento, por exemplo,

\footnotetext{
${ }^{1}$ Texto de uma conferência apresentada a convite da Prof. Doutora Ruth Gauer e do Prof. Doutor Jayme Paviani, no Congresso Luso-Brasileiro sobre Epistemologia e Interdisciplinaridade na Pos-Graduação, realizado em Porto Alegre, Brasil, na Pontifícia Universidade Católica do Rio Grande do Sul, nos dias 21, 22 e 23 de Junho de 2004. Agradeço a gravação e a transcrição da conferência, o que muito facilitou a redacção final deste texto.

* Professora da Faculdade de Ciências da Universidade de Lisboa (Departamento de Educação) e Coordenadora Científica do Centro de Filosofia das Ciências da Universidade de Lisboa (CFCUL) (http://cfcul.fc.ul.pt )

${ }^{2}$ Em termos de experiências, os primeiros relatos começam, tanto quanto sei, nos anos 60, por exemplo, com Vieira e Durval (1965), Freitag-Rouanet, (1991) e Fazenda (1998), oferecem elaboradas descrições das mais significativas experiências entretanto realizadas; em termos de investigação, ainda nos anos setenta, recordaria apenas Lruyten, (1973) e Japiassu (1976). Depois, a partir dos anos 90, Paviani (1993), Lück (1994), Carneiro Leão (1992), Portela (1992), Falenda (2002), Paviani e Botomé (2003).
} 
foi-me dito estarem em funcionamento mais de cem cursos e programas de mestrado interdisciplinares. Haverá, certamente, boas razões para isso. Atrevo-me a apontar apenas uma: pela sua juventude, flexibilidade e abertura ao novo, o Brasil tem condições extraordinárias para escutar as transformações a que a interdisciplinaridade procura responder e para saber adaptar-se e acompanhar essas transformações ${ }^{2}$.

Segunda observação: fiquei assustada quando, na amável apresentação que fez do meu curriculum, o Prof ${ }^{\mathfrak{o}}$ Paviani anunciou que eu iria explicar como se faz interdisciplinaridade. Pois bem, sei que vou desiludir-vos! Mas a verdade é que não vou dizer como se faz. Por uma razão muito simples que é meu dever confessar logo de início: é que eu não sei como se faz interdisciplinaridade. Aliás, indo um pouco mais longe, atrevo-me a pensar que ninguém sabe. A interdisciplinaridade é mesmo capaz de não ser qualquer coisa que se faça. Ela situa-se algures, entre um projecto voluntarista, algo que nós queremos fazer, que temos vontade de fazer e, ao mesmo tempo, qualquer coisa que, independentemente da nossa vontade, se está inexoravelmente a fazer, quer queiramos quer não. E é na tensão entre estas duas dimensões que nós, indivíduos particulares, na precariedade e na fragilidade das nossas vidas, procuramos caminhos para fazer alguma coisa que, por nossa vontade e porventura independentemente dela, se vai fazendo. Nestas circunstâncias, compreendem bem que eu não possa responder à questão sobre como se faz a interdisciplinaridade.

Outra confissão, ainda mais dramática. Para além de eu não saber como se faz interdisciplinaridade; mais, de me parecer que ninguém saberá; agora, esta minha nova confissão é bem mais grave: não só não sei como se faz, como também não sei o que é a interdisciplinaridade. Afirmação paradoxal para ser feita por alguém que atravessa o Atlântico para fazer uma conferência sobre interdisciplinaridade, que aceita o convite, faz a viagem e vem dizer que, afinal, não sabe o que é aquilo de que vem falar. É natural que os meus auditores se sintam defraudados e concluam: bom, se a conferencista não sabe aquilo de que vem falar, se é de facto como ela própria disse, então não nos resta senão irmo-nos embora.

Peço-vos um pouco de paciência. Talvez que, apesar de tudo, eu tenha alguma coisa minimamante interessante para vos dizer. O meu objectivo é desenvolver perante vós um esforço explicativo capaz de permitir compreender alguma coisa daquilo que se pensa sobre a interdisciplinaridade. Tentar compreender por que é que ninguém sabe como ela se faz e por que é que, pelo menos por enquanto, é impossível dizer o que é a interdisciplinaridade. Finalmente, tentar oferecer algum contributo para a compreensão do tema que o título desta minha conferência anuncia: Interdisciplinaridade e Integração dos Saberes.

Comecemos pelas palavras. Há uma intimidade, uma proximidade suave que exigimos ter com as palavras. Ora, a palavra interdisciplinaridade, logo do ponto de vista material, é uma palavra agreste, desagradável, comprida demais. Além disso, não há só uma. Há uma família de quatro elementos que se apresentam como mais ou menos equivalentes: pluridisciplinaridade, multidisciplinaridade, interdisciplinaridade e transdisciplinaridade. Sentimo-nos um pouco perdidos no conjunto destas quatro palavras. As suas fronteiras não estão estabelecidas, nem para aqueles que as usam, nem para aqueles que as estudam, nem para aqueles que as procuram definir. Há qualquer coisa estranha nesta família de palavras. Umas vezes são usadas umas, outras vezes outras. Há pessoas que gostam mais de uma e a usam em todas as circunstâncias, outras mais de outras. Como se fosse uma questão de gostar ou não gostar. Mas é assim que as coisas funcionam.

Por outro lado, temos que constatar que estas palavras estão muito gastas, muito banalizadas. Elas são usadas para as coisas mais diversas. Por exemplo, num colóquio, numa mesa redonda, num programa televisivo, convidam-se várias pessoas de várias disciplinas e colocam-se à volta de uma mesa. Cada pessoa fala na sua vez ou procura-se que conversem umas com as outras. 
Porém, a maior parte das vezes, o que acontece é desentenderem-se, caírem em mal entendidos, conflitos, falhas terríveis de comunicação. Não importa! Ingenuamente, pensa-se que o simples facto de estarem ao lado umas das outras, sentadas em volta de uma mesa (sobretudo se for "redonda"), permite dizer que a acção é interdisciplinar (Cf. GUSDORF, 1990, p. 29). Ora, em geral, isso nada tem a ver nem com a pluri, nem com a multi, nem com a trans, nem com a interdisciplinaridade. Ao contrário, na esmagadora maioria dos casos, isso tem tudo a ver com a disciplinaridade. Tem tudo a ver com a incapacidade que todos temos para ultrapassar os nossos próprios princípios discursivos, as perspectivas teóricas e os modos de funcionamento em que fomos treinados, formados, educados.

Não é só na comunicação social mas também na investigação e no ensino que isto acontece. Por exemplo, em muitas Escolas Secundárias e Universidades, são feitas experiências ditas interdisciplinares. Ora, o que acontece é que a palavra está lá, mas percebemos que a experiência em causa é insuficiente, que, muitas vezes, se resume a um acto legítimo, por certo, mas de pura “animação cultural”. Não de interdisciplinaridade. ${ }^{3}$ Quero eu dizer com isto que a palavra é pois ampla demais, que está a ser banalizada, aplicada a um conjunto muito heterogéneo de situações e experiências. E esta utilização excessiva gasta a palavra, esvazia-a, tira-lhe sentido.

Face esta situação, uma hipótese seria abandonar a palavra interdisciplinaridade e suas congéneres e procurar uma alternativa. Há hoje várias palavras nesta situação. Fala-se em integração dos saberes, em circuitos integrados, em integração europeia, fala-se em mundialização, globalização, etc. Ou seja, há de facto um conjunto de palavras alternativas de que nos socorremos para dar conta de qualquer coisa que, em grande parte, ou pelo menos parcialmente, se deixa pensar pela palavra interdisciplinaridade. Mas, a verdade é que, também a elas, não as sabemos definir com a necessária precisão. O problema não é pois facilitado mas agravado pela emergência de palavras alternativas. Neste situação, é urgente uma aproximação, um esforço para encontrar os contornos, ainda que aproximativos, de todas estas palavras, para as saber usar de forma suficientemente diferenciada.

Infelizmente, como vos confessei logo de início, não tenho uma definição precisa, exaustiva, completa da família de palavras a que a interdisciplinaridade pertence. Tenho unicamente uma proposta provisória de definição que passo a apresentar rapidamente. A minha proposta é muito simples. Passa por reconhecer que, por detrás destas quatro palavras, multi, pluri, inter e transdisciplinaridade, está uma mesma raiz - a palavra disciplina. Ela está sempre presente em cada uma delas. O que nos permite concluir que todas elas tratam de qualquer coisa que tem a ver com as disciplinas. Disciplinas que se pretendem juntar: multi, pluri, a ideia é a mesma: juntar muitas, pô-las ao lado uma das outras. Ou então articular, pô-las inter, em inter-relação, estabelecer entre elas uma acção recíproca. O sufixo trans supõe um ir além, uma ultrapassagem daquilo que é próprio da disciplina.

Aceitar a minha proposta como base de trabalho, como hipótese operatória, é aceitar que há qualquer coisa que atravessa a pluridisciplinaridade ou multidisciplinaridade, a interdisciplinaridade e a transdisciplinaridade. Que essa qualquer coisa é, em todos os casos, uma tentativa de romper o carácter estanque das disciplinas. Mas que essa tentativa se pode fazer em diferentes níveis, em diferentes graus. O primeiro é o nível da justaposição, do paralelismo, em que as várias disciplinas estão lá, simplesmente ao lado umas das outras, que se tocam mas que não interagem. Num segundo nível, as disciplinas comunicam umas com as outras, confrontam e discutem as suas perspectivas, estabelecem entre si uma interacção mais ou menos forte; num

\footnotetext{
${ }^{3}$ Apesar deste diagnóstico pessimista (estou, obviamente, a referir-me sobretudo ao caso português) há que assinalar um grande número de verdadeiras experiências interdisciplinares que, na esmagadora maioria dos casos, se ficam a dever, não a determinações legais ou mesmo a facilidades institucionais, mas à capacidade, entusiasmo e dedicação dos professores que constroem essas experiências. No livro A interdisciplinaridade: reflexão e experiência, de Pombo, Guimarães e Levy (1993), são apresentadas três experiências a este título muito eloquentes.
} 
terceiro nível, elas ultrapassam as barreiras que as afastavam, fundem-se numa outra coisa que as transcende a todas. Haveria, portanto, uma espécie de um continuum de desenvolvimento. Entre alguma coisa que é de menos - a simples justaposição - e qualquer coisa que é de mais - a ultrapassagem e a fusão - a interdisciplinaridade designaria o espaço intermédio, a posição intercalar. O sufixo inter estaria lá justamente para apontar essa situação. A minha proposta é pois tão simples como isto: partir da compreensão dos diferentes prefixos da palavra disciplinaridade, do que eles têm para nos ensinar, das indicações que transportam consigo, na sua etimologia. ${ }^{4}$

Mas, o mais importante não é tanto a questão nominal. O mais importante é compreender o que se deixa pensar nessas várias palavras. Tentar perceber o que por elas, e através delas, se dá a pensar. Aliás, é importante notar que, apesar de gastas e banalizadas, essas palavras são recorrentes, tenazes, persistentes. Esse seu constante regresso é prova de que alguma coisa de importante se está a tentar pensar por elas. Aqui, estou inteiramente de acordo com o diagnóstico que o Senhor Pró-Reitor acaba de fazer: ${ }^{5}$ aquilo que, de importante, se deixa pensar sob essa diversidade de palavras é a resistência à especialização. Por isso a interdisciplinaridade é o lugar onde se pensa hoje a condição fragmentada das ciências e onde, simultaneamente, se exprime a nossa nostalgia de um saber unificado.

Ora, o que é a especialização? Uma tendência da ciência moderna, exponencial a partir do século XIX. Sabemos que a ciência moderna se constitui pela adopção da metodologia analítica proposta por Galileu e Descartes. Isto é, se constituiu justamente no momento em que adoptou uma metodologia que lhe permitia "esquartejar" cada totalidade, cindir o todo em pequenas partes por intermédio de uma análise cada vez mais fina. Ao dividir o todo nas suas partes constitutivas, ao subdividir cada uma dessas partes até aos seus mais ínfimos elementos, a ciência parte do princípio de que, mais tarde, poderá recompor o todo, reconstituir a totalidade. ${ }^{6}$ A idéia subjacente é a de que o todo é igual à soma das partes.

O procedimento científico é este. Sempre foi este. É assim que a ciência tem funcionado. Já os gregos haviam chegado à concepção do átomo, a tomos, ou seja, daquilo que, justamente, é sem partes. E o átomo, limite para que tendeu a ciência moderna, foi também ele descoberto na sua estruturação interna. Continua a sê-lo. Ou seja, sob os nossos olhos, a ciência continua esse movimento em direcção a uma cada vez mais profunda especialização. Especialização que tem produzido resultados notáveis, magníficos. Não podemos recusar, nem menosprezar, nem esquecer, que foi este procedimento analítico da ciência moderna que deu origem a todos os conhecimentos e a todo o bem-estar que lhe devemos. Talvez não valha a pena reforçar aqui os seus aspectos positivos. Todos os conhecemos. A nossa vida depende deles a cada instante. Porém, se não podemos esquecer, diminuir, negar os benefícios da ciência moderna, tanto em termos de compreensão do mundo como de melhoria das nossas próprias vidas, isso não pode ser impeditivo do reconhecimento dos custos que a especialização trouxe consigo.

\footnotetext{
${ }^{4}$ Para uma apresentação mais detalhada desta proposta, remetemos de novo para Pombo, Guimarães e Lévy (1993, p. 11-4).

${ }^{5}$ Referimo-nos ao Prof. Doutor Urbano Zilles, actualmente Pró-Reitor de Pesquisa e Pós-Graduação da Pontifícia Universidade Católica do Rio Grande do Sul, que fez a abertura oficial do Congresso e que, já nos anos setenta, havia escrito dois interessantes estudos intitulados Pesquisa de carácter interdisciplinar na universidade (1974) e Interdisciplinaridade no ensino e na pesquisa (1979) nos quais esta tese era amplamente elaborada.
}

${ }^{6}$ Apesar de ter sido um dos mais poderosos inspiradores do método analítico e, como tal, das suas consequências em termos de especialização científica, a verdade é que Descartes, em momento algum, deixou de considerar, como o objectivo maior da Ciência, quer a totalidade como reconstituição do todo, quer a unidade das diversas disciplinas num esquema de conexões, integrado e globalizante. Como Descartes escreve, "sientiae inter se connexae" (AT, X361, p. 12-3). O que, paradoxalmente, poderia fazer dele um dos primeiros defensores da interdisciplinaridade. 
Em primeiro lugar, custos relativos ao próprio especialista que se transforma numa criatura estranha, alguém que sabe cada vez mais acerca de cada vez menos. Como diz Ortega Y Gasset, em páginas célebres de La rebelion de las massas (1929), numa das mais virulentas críticas à arrogância do especialista alguma vez traçadas:

Dantes os homens podiam facilmente dividir-se em ignorantes e sábios, em mais ou menos sábios e mais ou menos ignorantes. Mas o especialista não pode ser subsumido por nenhuma destas duas categorias. Não é um sábio porque ignora formalmente tudo quanto não entra na sua especialidade; mas também não é um ignorante porque é um 'homem de ciência' e conhece muito bem a sua pequeníssima parcelas do universo. Temos que dizer que é um 'sábio-ignorante', coisa extremamente grave pois significa que é um senhor que se comporta em todas as questões que ignora, não como um ignorante, mas com toda a petulância de quem, na sua especialidade, é um sábio (GASSET, 1929, p. 173-4).

Pouco depois, o mesmo tipo de diagnóstico começa a ser feito por grandes homens de ciência. Por exemplo, Norbert Wienner escrevia em 1948:

Há hoje poucos investigadores que se possam proclamar matemáticos ou físicos ou biólogos sem restrição. Um homem pode ser um topologista ou um acusticionista ou um coleopterista. Estará então totalmente mergulhado no Jargão do seu campo, conhecerá toda a literatura e todas as ramificações desse campo mas, frequentemente, olhará para o campo vizinho como qualquer coisa que pertence ao seu colega três portas abaixo no corredor e considerará mesmo que qualquer manifestação de interesse da sua parte corresponderia a uma indesculpável quebra de privacidade" (WIENER, 1948, p. 2).

E Oppenheimer, num texto de 1955, descreve nos seguintes termos esta mesma situação:

Hoje, não são só os nossos reis que não sabem matemática mas também os nossos filósofos não sabem matemática e, para ir um pouco mais longe, são também os nossos matemáticos que não sabem matemática. Cada um deles conhece apenas um ramo do assunto e escutam-se uns aos outros com um respeito fraternal e honesto. [...] $\mathrm{O}$ conhecimento científico hoje não se traduz num enriquecimento da cultura geral. Pelo contrário, é posse de comunidades altamente especializadas que se interessam muito por ele, que gostariam de o partilhar, que se esforçam por o comunicar. Mas não faz parte do entendimento humano comum... $\mathrm{O}$ que temos em comum são os simples meios pelos quais aprendemos a viver, a falar e a trabalhar juntos. Além disso, temos as disciplinas especializadas que se desenvolveram como os dedos da mão: unidos na origem mas já sem contacto (OPPENHEIMER, 1955, p. 55). 
Três anos mais tarde, outra voz se faz ouvir para denunciar, não tanto agora a pulverização disciplinar, mas o cisma profundo que se cavou entre duas formas da cultura científica. Referimo-nos a Lord C. P. Snow que, num pequeno texto de cerca de 50 páginas intitulado Two cultures, publicado em 1959 e, a partir daí, constantemente reeditado e traduzido em todas as línguas do mundo, dá conta da clivagem que, desde o início do século XIX estava já latente sob a forma de oposição entre ciências da natureza e ciências do espírito. Snow reencontra essa ruptura no seu tempo, em termos de diagnóstico, na existência de duas culturas que deixaram de se comunicar. "De um lado, os intelectuais literatos, do outro os cientistas. Entre os dois um hiato mútuo de incompreensão e, às vezes, particularmente entre os jovens, de hostilidade" (SNOW, 1959 , p. 4). A especialização é aqui sobretudo essa incomunicabilidade entre ramos fundamentais do que era antes "A cultura científica". Mas Snow vai mais longe e aponta como raiz dessa separação, o carácter incompleto dessas duas culturas. Diz ele: "os cientistas nunca leram uma obra de Shakespeare e os literatos não conhecem a segunda lei da termodinâmica" (SNOW, 1959, p. 15). Cada grupo desconhece e ignora o que o outro faz, chegando mesmo, em alguns casos, a considerar que o que o outro grupo faz não tem qualquer interesse.

Mas, também do ponto de vista institucional, a especialização tem consequências gravíssimas. Como sabem, a ciência é hoje uma enorme organização dividida internamente por inúmeras comunidades de pares, cada uma com os seus congressos, as suas revistas, as suas bibliotecas, os seus territórios, os seus espaços institucionais, etc. Essas comunidades constituem agregados competitivos que lutam por apoios, subsídios, financiamentos, bolseiros, novos equipamentos, etc. Já não se trata de os cientistas viverem de costas voltadas uns contra os outros, de desconhecerem o que estão a fazer os seus colegas "três portas abaixo no corredor". Trata-se agora de competir naquilo que deveria ser de todos, de cada um procurar defender os seus interesses particulares, se possível, retirando as benesses do colega do lado. ${ }^{7}$

Hoje em dia, por exemplo, está a desenvolver-se um tipo novo de patentificação de áreas de investigação, fenómeno que, na sua displicente ocorrência, ameaça destruir a nossa própria ideia de ciência. Durante muito tempo, como sabem, só se faziam patentes quando o investigador descobria qualquer coisa de novo, descoberta essa que, depois, patenteava. Isso ocorria sobretudo nas áreas das tecnologias. As leis, os princípios, as teorias, essas ficavam naturalmente à mercê de todos, ligadas ao nome daqueles que tinham apresentado pela primeira vez (ou de forma completa e consistente) o resultado da investigação. No caso das tecnologias, então sim, havia - e há - patentes para as mais diversas aplicações técnicas. Pois, neste momento, muitas instituições onde se faz investigação científica de ponta estão a patentear, não resultados obtidos, mas áreas de investigação. Quando um projecto de investigação se apresenta, com os seus objectos de investigação e a sua metodologia, antes mesmo de começar a trabalhar, a área seleccionada e a metodologia proposta são patenteadas. ${ }^{8}$ Qualquer coisa de muito estranho que vem pôr em causa a nossa ideia de ciência como saber universal, público, desinteressado. Sabíamos que, por diversas vezes na história da ciência, foram desenvolvidas pesquisas em simultâneo. Que diversos investigadores podiam ter uma mesma ideia, mais ou menos na mesma época e que, quando isso acontecia, estavamos perante um acontecimento festivo, um dos mais belos e significativos acontecimentos da racionalidade imanente à produção científica. A existência dessas descobertas simultâneas traduzia-se, em geral, no facto de os cientistas envolvidos serem consagrados em conjunto por uma mesma descoberta. Hoje, é tudo isto que está em ruína. O projecto de investigação demarca o seu terreno antes de haver qualquer descoberta, antes mesmo de iniciar verdadeiramente a investigação que se propõe fazer. Para que outros não possam trabalhar no mesmo objecto, para inviabilizar ou dificultar tanto quanto

\footnotetext{
${ }^{7}$ Para uma análise detalhada do fenómeno da especialização da ciência e suas consequências institucionais, cf., em especial, Weinberg (1967), Whitley (1976), Knorr, Krohn e Whitley (1980) e, mais recentemente, um livro penetrante de Isabelle Stengers (1993).

${ }^{8}$ Para mais detalhes sobre esta questão, veja-se Levy (2003), (paper gentilmente cedido pela autora).
} 
possível as descobertas simultâneas. E, nesse movimento, se esfuma o carácter público, universal e desinteressado da ciência.

Ora, tudo isto é uma consequência da especialização. Como se explica esta vontade de patentificação precoce? Não é certamente porque os investigadores sejam hoje mais perversos do que antigamente, ou tenham maus instintos, ou falta de modéstia, ou sejam incapazes de colaboração. Não! É porque, sendo a ciência cada vez mais cara, os investigadores precisam de grandes financiamentos. E, para tal, precisam de garantir lucros das suas descobertas futuras. E, para garantir lucros antecipados, têm que obter financiamento de empresas que, em troca, ficam com o direito de aplicar imediatamente as descobertas que os seus programas de investigação se propõem realizar. Ora, para darem esse financiamento, essas empresas exigem que as áreas de pesquisa sejam patenteadas antes que outras empresas se possam dedicar a essa mesma investigação científica (ou será exploração?). Não são pois os investigadores mas as próprias empresas que financiam as pesquisas que, à partida, colocam como condição do seu financiamento, a existência de resultados precisos e altamente especializadas, susceptíveis desse tipo de patentificação. Outras vezes, a investigação altamente especializada faz-se em laboratórios comandados por generais. Nesse caso, não são sequer necessárias patentes antecipadas. O que é necessário é garantir o segredo da investigação que está a ser desenvolvida, o silêncio do investigador-funcionário. Por outras palavras, estamos perante custos institucionais de uma lógica de especialização cada vez mais feroz.

Mas, para lá dos custos culturais e institucionais de uma ciência altamente especializada, há outros tipos de custos que importa referir, nomeadamente, a questão da heurística. É que, paradoxalmente, no estado de enorme avanço em que a nossa ciência se encontra, o progresso da investigação faz-se, cada vez mais, não tanto no interior dos adquiridos de uma disciplina especializada, mas no cruzamento das suas hipóteses e resultados com as hipóteses e os resultados de outras disciplinas. Ou seja, num número cada vez maior de casos, o progresso da ciência, a partir sobretudo da segunda metade do século XX, deixou de poder ser pensado como linear, resultante de uma especialização cada vez mais funda mas, ao contrário e cada vez mais, depende da fecundação recíproca, da fertilização heurística de umas disciplinas por outras, da transferência de conceitos, problemas e métodos - numa palavra, do cruzamento interdisciplinar. Trata-se de reconhecer que determinadas investigações reclamam a sua própria abertura para conhecimentos que pertencem, tradicionalmente, ao domínio de outras disciplinas e que só essa abertura permite aceder a camadas mais profundas da realidade que se quer estudar. Estamos perante transformações epistemológicas muito profundas. É como se o próprio mundo resistisse ao seu retalhamento disciplinar.

Gostaria de chamar a vossa atenção para um autor que tem tratado esta questão de um forma muito interessante. Refiro-me a Gilbert Durand para quem "a passividade monodisciplinar" é inibidora do "salto heurístico" de que a ciência moderna necessita, salto esse que, por natureza, sempre esteve e continua a estar "dependente de uma larga informação e cooperação interdisciplinar" (DURAND, 1991, p. 40-1). Aliás, a interdisciplinaridade tem - e sempre teve um lugar decisivo na criação científica. Como recorda Gilbert Durand,

[...] os sábios criadores do fim do século XIX e dos dez primeiros anos do século XX (esse período áureo da criação científica, em que se perfilam nomes como os de Gauss, Lobatchevski, Riemann, Poincaré, Hertz, Becquerel, os Curie, Rutherford, Pasteur, Max Plank, Bohr, Einstein), tiveram todos uma formação largamente pluridisciplinar, herdeira do velho trivium (as humanidades) e do quadrivium (os conhecimentos quantificáveis e, portanto, também a música) medievais (DURAND, 1991, p. 36). 
Daí que, a seu ver, o paradoxo está no facto de termos, "de um lado, um ensino cada vez mais especializado, do outro, um procedimento heurístico que necessita - sob pena de esterilidade da interdisciplinaridade"(DURAND, 1991, p. 34). Trata-se de compreender que o progresso do conhecimento não se dá apenas pela especialização crescente, como estávamos habituados a pensar. A ciência começa a aparecer como um processo que exige também um olhar transversal. Há que olhar para o lado para ver outras coisas, ocultas a um observador rigidamente disciplinar.

O que significa que, assim sendo, a interdisciplinaridade não é qualquer coisa que nós tenhamos que fazer. É qualquer coisa que se está a fazer quer nós queiramos ou não. Nós estamos colocados numa situação de transição e os nossos projectos particulares não são mais do que formas, mais ou menos conscientes, de inscrição nesse movimento. Podemos compreender este processo e, discursivamente, desenhar projectos que visam acompanhar esse movimento, ir ao encontro de uma realidade que se está a transformar, para além das nossas próprias vontades e dos nossos próprios projectos. Ou podemos não perceber o que se está a passar e reagir pela recusa da interdisciplinaridade ou pela sua utilização fútil, superficial, como se se tratasse de um mero projecto voluntarista formulado no contexto de uma simples moda, passageira como todas as modas.

Perceber a transformação epistemológica em curso é perceber que lá, onde esperávamos encontrar o simples, está o complexo, o infinitamente complexo. Que quanto mais fina é a análise, maior a complexidade que se abre à nossa frente. E, portanto, que o todo não é a soma das partes. Esta é, penso eu, uma das chaves fundamentais para o entendimento desta questão. Colocado na ordem do dia pelos desenvolvimentos de diversas ciências (das matemáticas, às ciências da natureza e às ciências humanas), este simples enunciado - "o todo não é a soma das partes" - tem tido um impacto e uma influência extraordinária na nossa ciência e na nossa maneira de pensar a questão da interdisciplinaridade. É que, se o todo não é a soma das partes, a especialização tem que ser complementada, ou mesmo em alguns casos substituída, por uma compreensão interdisciplinar capaz de dar conta das configurações, dos arranjos, das perspectivas múltiplas que a ciência tem que convocar para o conhecimento mais aprofundado dos seus objectos de estudo. Ou seja, o problema da especialização encontra os seus limites justamente aqui, no momento em que a ciência toma consciência que o todo não é a soma das partes.

É nesta nova situação epistemológica que se têm vindo a constituir novos tipos de disciplinas. Umas têm sido designadas como ciências de fronteira, novas disciplinas que nascem nas fronteiras entre duas disciplinas tradicionais. Como exemplos, refiram-se a bioquímica, a biofísica, etc. Outras, como interdisciplinas, aquelas que nascem na confluência entre ciências puras e ciências aplicadas. O primeiro exemplo foi o da investigação operacional, o mais eloquente é o da engenharia genética, duas áreas - a engenharia e a genética - cuja mistura era impensável há 60 a 70 anos. Finalmente há quem considere a existência de interciências que seriam conjuntos disciplinares onde não há já uma ciência que nasce nas fronteiras de duas disciplinas fundamentais (ciências de fronteira) ou que resulta do cruzamento de ciências puras e aplicadas (interdisciplinas) mas que se ligam, de forma descentrada, assimétrica, irregular, numa espécie de patchwork combinatório que visa a constituição de uma nova configuração disciplinar capaz de resolver um problema preciso. O exemplo melhor é o das ciências cognitivas. Elas não são especialmente a psicologia e a neurocirurgia, são as neurociências, são a filosofia, são a matemática, são as ciências da computação. Ou seja, são conjuntos de disciplinas que se encontram de forma irregular e descentrada para colaborar na discussão de um problema comum ${ }^{9}$.

\footnotetext{
${ }^{9}$ Remetemos para um livro da minha autoria, Interdisciplinaridade: ambições e limites, onde se faz um estudo detalhado do estatuto disciplinar das ciências cognitivas. Cf. Pombo (2004, p. 78-87).
} 
Além da constituição de novas disciplinas, assistimos hoje à proliferação de novas práticas de investigação interdisciplinar ${ }^{10}$ e mesmo à constituição de novos problemas. Problemas grandes demais, problemas complexos, que se não deixam pensar em laboratório porque comportam um número enorme de variáveis, problemas que nenhuma disciplina está preparada para resolver. A juventude urbana, o envelhecimento, a violência, o clima ou a manipulação genética, por exemplo, são novidades epistemológicas a que só a interdisciplinaridade tem condições para procurar dar resposta.

Novas disciplinas, novas práticas, novos problemas. Daqui decorrem duas consequências importantes: o alargamento do conceito de ciência e a necessidade de reorganização das estruturas da aprendizagem das ciências, nomeadamente, a universidade.

No que diz respeito ao alargamento do conceito de ciência, apenas chamar a atenção para o facto de, desde o início do século XX, a ciência ter entrado num processo de perda da sua tão reclamada autonomia. Sabemos que, constituída por uma comunidade fechada, a ciência sempre se pensou autónoma, produtora de uma verdade de cujos critérios, ritmos e resultados era a única e legítima responsável. Eram os cientistas que estabeleciam as regras da sua actividade, constituíam os seus objectos de estudo, escolhiam as suas metodologias, validavam os seus resultados. Quem é que, fora da comunidade científica, se dava o direito de dizer se um determinado enunciado era cientifico ou não, se um resultado era válido ou não? Nem o homem comum, nem os grandes senhores, nem sequer o estado, tinham legitimidade, ou sequer capacidade, para se pronunciar sobre as prioridades ou a validade dos resultados da ciência. ${ }^{11}$ Como defendia Humbolt, aquando da reforma da Universidade de Berlim, aos governantes cabia unicamente proteger a autonomia da ciência e pagar o trabalho livre e independente dos seus praticantes. $^{12}$

Porém, a partir da segunda guerra mundial, a situação alterou-se. A ciência tornou-se porosa à política, deixou-se penetrar pela economia. Ao aceitar profissionalizar-se, passou a definir-se como actividade orientada, não tanto pelo desejo de verdade, mas pela capacidade de produção de resultados práticos imediatamente aplicáveis na esfera política, militar ou económica. ${ }^{13}$ Como diz Jean Hamburger, a atitude dos poderes políticos e económicos em relação à ciência deixou de ser o laissez-faire para passar a ser o "faire faire". ${ }^{4}$ Simultaneamente, a ciência passou a contaminar as mais reconditas dobras da nossa vida. É assim que, hoje, não apenas assistimos de fora ao épico, e por vezes trágico, ${ }^{15}$ "espectáculo da ciência", como, no interior das nossas vidas, somos constantemente convidados, não apenas a usar tudo que a ciência trouxe para facilitar a

\footnotetext{
${ }^{10}$ Para uma tipologia dessas práticas, remetemos de novo para Pombo (2004, p. 91-7).

11 Curiosamente, no século XX, até aos finais da década de 60, quase todas as epistemologias eram internalistas, isto é, defendiam a autonomia da ciência. Bachelard, por exemplo, dirá que a ciência se constrói por afastamento e ruptura face ao conhecimento vulgar (desqualificação do "antes" face ao "depois", do não-científico face ao científico). A opinião constitui um "obstáculo" ao progresso da ciência. A ciência é anti-opinião, contra a opinião. Numa formula célebre: "A opinião pensa mal; ela não pensa. [...] Nada se pode fundar sobre a opinião: é preciso antes destruí-la" (BACHELARD, 1938, p. 14). Também Kuhn, ao defender as virtudes da estabilidade do paradigma, reforça a autonomia da comunidade científica face às suas margens. Ao negar a ideia de que a ciência produz verdade, valoriza ao extremo o paradigma no interior do qual unicamente essa questão se pode colocar, e, portanto, fecha a comunidade sobre si mesma. A mesma imagem trabalha a epistemologia de Popper. A controvérsia que constitui o motor da ciência é "da" e "na" comunidade científica que se realiza. O terceiro mundo é completamente autónomo.

${ }^{12}$ Este tipo de afirmação, frequente nos textos programáticos de Humboldt, pode encontrar-se, por exemplo, num texto de 1909 cuja tradução francêsa de André Lacks, com o título "Sur l'organization interne et externe des établissements supérireurs à Berlin", se pode encontrar in Ferry, Person e Renault (1979, p. 322).

${ }^{13}$ É esse o sentido das posições de Habermas (1968) e Lyotard (1979) relativamente à racionalidade meramente operatória da ciência contemporânea.

${ }^{14}$ Cf. Hamburger (1986, p. 8).
} 
vida do homem, como a reconhecer a proximidade fundamental que nos liga à ciência e que liga a ciência ao nosso quotidiano.

Por outras palavras, a alargamento do conceito de ciência é tão profundo que, muitas vezes, é difícil estabelecer a fronteira entre a ciência e a política, a ciência e a economia, a ciência e a vida das comunidades humanas, a ciência e a arte, e assim por diante.

Situação que reclama, qual seu contraponto, um público cada vez mais informado, capaz de se interessar, de se inquietar, de mesmo exigir, criticar, protestar, resistir. ${ }^{16}$ Situação que, portanto, arrasta consigo uma transformação profunda da universidade, essa decisiva instituição humana que não é apenas uma escola, mas também é uma escola. Ora, na medida que a universidade não é uma escola, na medida em que ela é um polo de investigação, um lugar de produção de conhecimento novo, ela vai ter que acompanhar as trasformações da ciência contemporânea, o mesmo é dizer, vai ter que adoptar, e simultaneamente apoiar, as exigências interdisciplinares que atravessam hoje a construção de novos conhecimentos. E, para isso, vai ter que repensar as formas clássicas de articulação disciplinar, vai ter que reorganizar as suas divisões internas em faculdades e departamentos. Ou seja, aquilo que hoje é pedido às universidades, o que está a acontecer - mais na vossa e menos na minha - é justamente a constituição de institutos, centros, laboratórios e projectos de investigação interdisciplinares, de programas interdepartamentais de mestrado e doutoramento, de cursos flexíveis nos quais os estudantes possam encontrar seu próprio (per)curso por entre a variedade de cadeiras, módulos, seminários que lhes são propostos. Sabemos que as universidades que adoptam o modelo alemão, aquelas que têm por unidade base o instituto de investigação e que funcionam em regime de creditação, estão muito mais preparadas para esse tipo de trabalho do que as universidades napoleónicas (às quais pertencem as portuguêsas), aquelas que têm uma tradição altamente centralizada, tanto do ponto de vista administrativo como curricular e que, por essa razão, se encontram clivadas em faculdades e departamentos. De qualquer modo, o que está a acontecer em todas as universidades - mais na vossa e menos na minha - é que, mais cedo ou mais tarde, todas elas têm que acompanhar a inteligência interdisciplinar da ciência contemporânea.

Mas, se a universidade não é apenas uma escola, a verdade que ela também é uma escola e, enquanto escola, ela tem que preparar para a interdisciplinaridade. Ela tem que perceber as transformações epistemológicas em curso e, de alguma maneira, ir ao seu encontro. Ela tem que se preparar, não apenas para não oferecer resistências ao trabalho interdepartamental mas para, além disso, promover esse tipo de experiências, facilitar novos tipos de configurações disciplinares, aceitar fazer investigação sobre os novos problemas que se colocam à ciência contemporânea. Criar, se possível, circunstâncias e mecanismos que favoreçam a compreensão dos próprios fenómenos interdisciplinares que estão a ocorrer na ciência e na universidade. Por exemplo, 1) tornando viável a constituiçäo e desenvolvimento dos novos campos interdisciplinares de investigaçäo e ensino que o progresso do conhecimento científico requer; 2) promovendo o desenvolvimento de atitudes, hábitos e formas de trabalho interdisciplinares; 3 ) fomentando a prática de um ensino que promova uma integração dos saberes cada vez mais profunda; 4) apoiando a constituição de programas de investigação e de ensino em História das

\footnotetext{
15 Do lado épico, refiram-se, por exemplo, as grandes descobertas do início do século (como o rádio por Pierre e Marie Curie em 1898, ou a penicilina em 1928, por Fleming) ou as grandes viagens interplanetárias (de Yuri Gagarin, o primeiro homem no espaço em 1961, ou a descida na Lua de Neil Arsmtrong em 1969); do lado trágico, referiremos unicamente Hiroshima (1945), os desastres do Challenger e o acidente atómico de Chernobyl, ambos no ano fatídico de 1986.

${ }^{16}$ Para um estudo das transformações da relação entre a ciência e o público, veja-se I. Stengers (1993) que, de forma extremamente pertinente e sugestiva, mostra como, de cidadãos incompetentes, o público se está a transformar num conjunto de individuos capazes de participar activa e criticamente face aos projectos e resultados da ciência contemporânea. Sobre este mesmo assunto e suas determinações específicas no ensino das ciências, veja-se ainda Pombo (2002)
} 
Ciências, em Epistemologia, em Filosofia das Ciências. Em todos os casos, o objectivo é criar oportunidades sérias para pensar o que está a acontecer, tanto na esfera da produção, como na da transmissão do conhecimento. Procurar perceber a que corresponde o apelo interdisciplinar que atravessa a ciência contemporânea e que, timidamente, emerge nessa universidade e em todas universidades do mundo. Perceber que a interdisciplinaridade não é uma questão de moda, que há qualquer coisa de decisivo que nela se diz e por ela se procura pensar.

$* * *$

Finalmente uma última palavra para dizer que a interdisciplinaridade se deixa pensar, não apenas na sua faceta cognitiva - sensibilidade à complexidade, capacidade para procurar mecanismos comuns, atenção a estruturas profundas que possam articular o que aparentemente não é articulável - mas também em termos de atitude - curiosidade, abertura de espírito, gosto pela colaboração, pela cooperação, pelo trabalho em comum. Sem interesse real por aquilo que o outro tem para dizer não se faz interdisciplinaridade. Só há interdisciplinaridade se somos capazes de partilhar o nosso pequeno domínio do saber, se temos a coragem necessária para abandonar o conforto da nossa linguagem técnica e para nos aventurarmos num domínio que é de todos e de que ninguém é proprietário exclusivo. Não se trata de defender que, com a interdisciplinaridade, se alcançaria uma forma de anular o poder que todo saber implica (o que equivaleria a cair na utopia beata do sábio sem poder), mas de acreditar na possibilidade de partilhar o poder que se tem, ou melhor, de desejar partilhá-lo. Como? Desocultando o saber que the corresponde, explicitando-o, tornando-o discursivo, discutindo-o.

Ao contrário da fórmula repetida segundo a qual a nossa liberdade começa quando termina a liberdade do outro, para arriscar fazer interdisciplinaridade é necessário perceber que a nossa liberdade só começa quando começa a liberdade do outro. Ou seja, temos que dar as mãos e caminhar juntos.

\section{Referências}

BACHELARD, G. La formation de l'esprit scientifique: contribution à une psychanalyse de la connaissance objective. Paris: Vrin, 1975.

CARNEIRO LEÃO, E. Pour une critique de l'interdisciplinarité. In : PORTELLA, E. (Ed.). Entre savoirs: l'interdisciplinarité en actes: enjeux, obstacles, résultats. Toulouse: Èrès: Unesco, 1992. p. 333-47,

DURAND, G. Multidisciplinarités et heuristique. In: PORTELLA, E. (Org.). Entre savoirs: l'interdisciplinarité en actes: enjeux, obstacles, résultats. Toulouse: Érès: Unesco, 1991. p. 35-48.

FALENDA, I. C. A interdisciplinaridade: história, teoria e pesquisa. São Paulo: Papirus, 2003.

FAZENDA, A. La Formation des enseignants pour l'interdisciplinarité: une synthèse des recherches effectuées au Brésil. Revue des Sciences de l'Éducation, v. 24, n. 1, p. 95-114, 1998.

FERRY, L.; PERSON, J. P.; RENAULT, A. (Ed.). Philosophies de l'université : l'idéalisme allemand et la question de l'université. Paris: Payot, 1979. 
FREITAG-ROUANET, B. Alphabétisation et développement humain au Brésil. In: PORTELlA, E. (Org.). Entre Savoirs: l'interdisciplinarité en acte: enjeux, obstacles, perspectives. Toulouse: Ères: Unesco, 1991. p. 211-25.

GASSET, O. La rebelion de las massas. Madrid: Revista de Occidente, 1970. 1. ed. 1929.

GUSDORF, G. Les modéles épistémologiques dans les sciences humaines. Bulletin de Psychologie, n. 397, t. 43, fasc. 18, p. 858-68, 1990.

HABERMAS, J. Technick und Wissenschaft als Ideologia. Lisboa: Edições 70, 1987. 1. ed. 1968.

HAMBURGER, J. (Org.). La philosophie des sciences aujourd'hui. Paris: Gauthier-Villars, 1986.

JAPIASSU, H. Interdisciplinaridade e patologia do saber. Rio de Janeiro: Imago, 1976.

LEVY, T. Is the publicity of science in danger? In: INTERNATIONAL HISTORY, PHILOSOPHY AND SCIENCE TEACHING CONFERENCE, 7., 2003, Winnipeg.

Proceedings...Winnipeg: [s.n., 2003?].

LRUYTEN, N. A. A interdisciplinaridade: meio privilegiado para exercer a função crítica e espiritual. Atualização, p. 1059-69, 1973.

LÜCK, H. Pegadogia da interdisciplinaridade: fundamentos teórico-metodológicos. Petropolis: Vozes, 1994.

LYOTARD, J. F. A condição pós-moderna. Lisboa: Gradiva, 1989.

McLUHAN, M. La galaxie Gutenberg. Paris: Gallimard, 1977.

OPPENHEIMER, J. R. La science et le bon sens. Paris: Gallimard, 1955.

PAVIANI, J. Disciplinaridade e interdisciplinaridade. Revista de Estudos Criminais, v. 3, n. 12, p. 59-85, 2003.

PAVIANI, J.; BOTOMÉ, S. P. Interdisciplinaridade: disfunções conceituais e enganos acadêmicos. Caxias do Sul: Educs, 1993.

POMBO, O. Comunicação e construção do conhecimento científico. In: recta e o círculo, Lisboa: Relógio d'Água, 2002. p. 182-227. . A escola, a . Interdisciplinaridade: ambições e limites. Lisboa: Relógio d’Água, 2004.

POMBO, O.; GUIMARÃES, H.; LEVY, T. Interdisciplinaridade: reflexão e experiência. Lisboa: Texto, 1993.

PORTELLA, E. (Org.). Entre savoirs: l'interdisciplinarité en actes: enjeux, obstacles, résultats. Toulouse: Érès:Unesco, 1992.

SNOW, C. P. The two cultures and a second look: an extended version of the two cultures and the scientific revolution. London: Cambridge University Press, 1964.

STENGERS, I. L'invention des sciences modernes. Paris : Flammarion, 1995. 1. ed. 1993. 
KNORR, K.; KROHN, R.; WHITLEY, R. (Ed.). The social process of scientific investigation. London: D. Reidel Publishing Company, 1980.

WEINBERG, A. M. Reflexions on big science. Cambridge, MA: The MIT Press, 1967.

WIENER, N. Cybernetics, or Control and communication in the animal and the machine. Cambridge, MA: The MIT Press, 1967. 1. ed. 1948.

WHITLEY, R. Umbrella and polytheistic scientific disciplines and their elites. Social Studies of Science, v. 6, n. 3-4, 471-97, 1976.

VIEIRA; DURVAL. A coordenação das disciplinas no curso ginasial. Revista Pedagogia, v.11, n. 19/20, 102-40, 1965.

ZILLES, U. Pesquisa de carácter interdisciplinar na universidade. Convivium, v. 17, n. 3, p. 241$53,1974$.

. Interdisciplinaridade no ensino e na pesquisa. Revista do Centro de Ciências Sociais e Humanas, v. 4, n. 2, p. 225-36, 1979. 